\title{
FENOMENA URBANISASI : POLA PERUBAHAN MATA PENCAHARIAN BERBASIS SPASIAL
}

\author{
Siti Nuurlaily Rukmana ${ }^{1)}$ dan Moch. Shofwan ${ }^{2)}$ \\ ${ }^{1)}$ 2) Program Studi Perencanaan Wilayah dan Kota, Universitas PGRI Adi Buana Surabaya \\ Email : nuurlailyrukmana@gmail.com
}

\begin{abstract}
Abstrak
Fenomena transformasi perkotaan merupakan salah satu penyebab dari terjadinya urbansasi. Urbanisasi ditandai dengan pertumbuhan demografi yang meningkat setiap tahunnya. Hal ini mendorong ketidakseimbangan antara penyediaan lahan dengan permintaan lahan sebagai aspek kegiatan atau tempat tinggal. Kecenderungan terjadinya perluasan wilayah sangat tinggi khususnya di kawasan pinggiran. Kecamatan Krian merupakan salah satu daerah yang mengalami perubahan lahan cukup tinggi. Tujuan artikel ini untuk menilai dan menganalisis pola perubahan mata pencaharian di Kecamatan Krian. Teknik analisis pada studi ini dengan menggunakan Geographical Information System melalui pendekatan kualitatif. Berdasarkan hasil analisis bahwa perubahan mata pencaharian (khususnya petani menjadi non petani) berada pada sisi timur. Terdapat 3 desa yang mengalami penurunan jumlah petani mulai tahun 1995-2015 yaitu Desa Keboharan, Tarung Wetan dan Jatikalang. Hal ini disebabkan di sisi timur secara administrasi lokasi tersebut strategis yaitu terletak di pertigaan bypass dan dibagian utara berbatasan dengan kabupaten Gresik. Sehingga memicu adanya perubahan aktivitas, yaitu sebagai tempat hunian. Artinya di sisi timur Sidoarjo tidak digunakan sebagai tempat aktivitas kerja masyarakat melainkan sebagai tempat tinggal.
\end{abstract}

Kata Kunci: Mata Pencaharian, Pinggiran, Urbanisasi

\begin{abstract}
The phenomenon of urban transformation is one of the causes of the occurrence of urbanization. Urbanization is characterized by increasing demographic growth every year. This encourages an imbalance between the provision of land and the demand for land as an aspect of activity or residence. The tendency of regional expansion is very high, especially in the periphery. Krian Subdistrict is one of the areas that has experienced high land changes. The purpose of this article is to assess and analyze patterns of livelihood changes in Krian District. The analysis technique in this study uses the Geographical Information System through a qualitative approach. Based on the results of the analysis that changes in livelihoods (especially farmers become nonfarmers) are on the east side. There were 3 villages that experienced a decline in the number of farmers from 1995-2015, namely Keboharan, Terung Wetan and Jatikalang Villages. This is due to the east side administratively the location is strategically located at the bypass T-junction and the Gresik regency in the north. So that triggers a change in activity, namely as a place to live. This means that on the east side of Sidoarjo it is not used as a place for community work activities but as a place to live.
\end{abstract}

Keywords : Livelihood, Peri-urban, Urbanization 


\section{PENDAHULUAN}

Salah satu permasalahan perkotaan yaitu terjadi pada fenomen urbanisasi. Hal ini disebabkan adanya ketidakseimbangan antara ketersediaan lahan dengan permintaan masyarakat akan kebutuhan aktivtas atau bermukim. Artinya ketika segala aktifitas memusat di perkotaan, maka kecenderungan permintaan akan kebutuhan lahan tinggi, khususnya sebagai tempat bermukim (Samat, 2011). Dampak dari fenomena tersebut menjadikan masyarakat cenderung untuk memilih bermukim di kawasan sekitar perkotaan, yaitu di kawasan pinggiran. . Harga dan jarak yang terjangkau menjadikan salah satu dari pilihan masyarakat pada umumnya, dan hal menyebabkan terjadinya trannsformasi perkotaan di sekitar kawasan pinggiran.

Fenomena transformasi perkotaan menuju kawasan pinggiran juga merupakan salah satu bukti bahwa kota memiliki sifat dinamis. Bentuk kota yang dinamis dimulai dari adanya berbagai aktivitas yang sebagai alat untuk mendorong manyarakat untuk melakukan perpindahan penduduk, sehingga angka jumlah penduduk yang meningkat (Simon, 2008); (Aguilar, 2008). Salah satu bukti terjadinya perluasan perkotaan yaitu adanya perubahan lahan (Manaugh, Badami, \& El-geneidy, 2015) dan berkembanganya lahan terbangun (Xiao, Shen, Ge, Tateishi, \& Tang, 2006).

Fenomena urbanisasi ini terimplementasi juga di Kabupaten Sidoarjo sebagai daerah yang terletak di sekitar Kota Surabaya. Seperti yang dijelaskan pada RTRW (2009) bahwa wilayah inti Gerbangkertasusila Plus adalah Surabaya, sebagian Gresik, sebagian Sidoarjo, sebagian Bangkalan dengan aktifitas kegiatan di dominasi kegiatan industri, perdagangan dan jasa, serta kegiatan pemerintahan Regional Jawa Timur. Dampak dari fenomena tersebut salah satunya adalah perubahan mata pencaharian

Tujuan artikel ilmiah ini yaitu untuk menilai dan menganalisis pola perubahan mata pencaharian secara spasial. Penelitian ini fokus di Kecamatan Krian Kabupaten Sidoarjo. Adapun batas administrasi pada penelitian ini sebagai berikut:

Utara : Kabupaten Gresik

Barat : Kecamatan Balengbendo

Selatan : Kecamatan Wonoayu

Timur : Kecamatan Taman

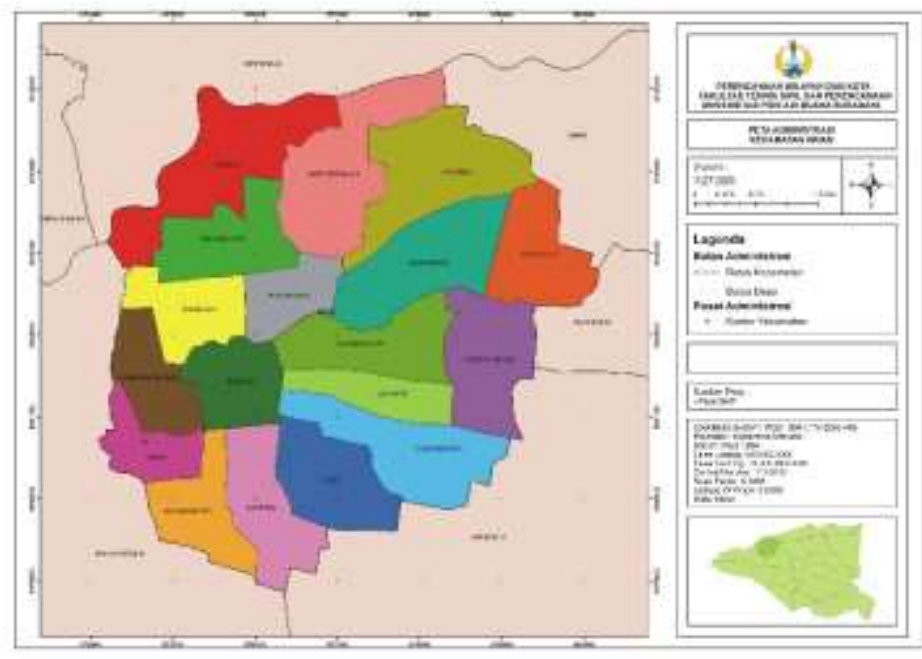

Gambar 1. Peta Administrasi dan Guna Lahan Kecamatan Krian

\section{METODOLOGI}

\section{1) Pengumpulan Kebutuhan Data}

Metode pengumpulan data merupakan salah satu prosedur untuk mendapatkan kondisi riil pada suatu penelitian. Pada tahap pengumpulan data dilakukan pemahaman terhadap karakteristik dari variabel yang akan diamati pada wilayah studi. Metode 
pengumpulan data ditinjau dari berbagai sumber data, yaitu:

1. Sumber data primer

Survei data primer merupakan survei yang dilakukan dengan turun langsung ke lapangan atau obyek studi. Dalam pengumpulan data primer dilakukan dengan dua cara pendekatan :

a. Observasi

Secara luas observasi atau pengamatan berarti setiap kegiatan untuk melakukan pengukuran, akan tetapi observasi atau pengamatan disini diartikan yaitu pengamatan dengan menggunakan indera penglihatan yang tidak mengajukan pertanyaan-pertanyaan

\section{b. Wawancara}

Teknik wawancara dapat dilakukan untuk mendapatkan data dari pemerintah/stakeholder, swasta, dan masyarakat sehingga data hasil wawancara tersebut dapat dijadikan bahan untuk mengkaji pola perubahan mata pencaharian.

2. Sumber data sekunder

Data sekunder adalah data yang didapatkan dengan tidak turun langsung ke lapangan melainkan mengumpulkan data atau informasi dari beberapa sumber seperti instansi terkait dan literatur.

\section{2) Teknik Analisis Data}

Teknik analisis data yang dilakukan dalam penelitian ini dapat dilihat pada tabel 1

Tabel 1. Teknik Analisis Data

\begin{tabular}{|c|c|c|}
\hline $\begin{array}{c}\text { Sasaran } \\
\text { Penelitian }\end{array}$ & Teknik & Output \\
\hline $\begin{array}{l}\text { Menganalisis } \\
\text { pola perubahan } \\
\text { mata } \\
\text { pencaharian }\end{array}$ & $\begin{array}{l}\text { Geographical } \\
\text { Information } \\
\text { System melalui } \\
\text { pendekatan } \\
\text { kualitatif }\end{array}$ & $\begin{array}{l}\text { Pola perubahan } \\
\text { mata } \\
\text { pencaharian } \\
\text { berbasis spasial }\end{array}$ \\
\hline
\end{tabular}

\section{HASIL DAN PEMBAHASAN}

Pola Perubahan Mata Pencaharian

Transformasi spasial memiliki definisi yang berbeda-beda. Yunus (2008) menyampaikan bahwa transformasi spasial merupakan artikulasi dari kegiatan manusia yang ada di muka bumi ini. Transformasi spasial wilayah dapat berupa perubahan bentuk pemanfaatan lahan, harga lahan, jumlah dan kepadatan penduduk, perubahan karakteristik permukiman, karakteristik bangunan dan juga aksesibilitas. Pada artikel ilmiah ini fokus pada mata pencaharian yaitu petani menjadi non pertani.

Terjadinya perubahan mata pencaharian diawali dari penurunan produksi dan produktivitas pertaniannya dimana disebabkan karena adanya gangguan, salah satunya seperti polusi air irigasi yang disebabkan oleh limbah rumah tangga. (dimana adanya perluasan lahan terbangun) maupun industri dan debu-debu di sepanjang jalan raya yang menempel pada daun-daun tanaman pertanian (Yunus, 2008). Hal ini tentunya berdampak pad kerusakan tanaman pertanian. Sehingga ketika jumlah produksi pertanian berkurang maka penghasilan para petani juga mengalami penurunan. Hal tersebut yang mendorong petani untuk menjual lahan pertaniannya dan kemudian berpindah profesi menjadi non pertanian.

$\begin{array}{llr} & \text { Kecamatan krian mulai } & \text { tahun } \\ 1995 \text { sampai } & \text { tahun 2015 } & \text { telah } \\ \text { mengalami } & \text { transformasi } & \text { mata }\end{array}$ pencaharian. Pada penelitian ini dapat dilihat perubahan jumlah petani (Gambar 2) dan buruh industri (Gambar 3) mulai tahun 1995 hingga 2015.Berdasarkan hasil analis dapat diketahui bahwa pola perubahan mata pencaharian lebih mengarah pada sisi timur. Pada mata pencaharian petani di tahun 1995 paling tinggi terletak di sisi barat (Desa Tambakemerakan dan Desa Kemasan) dan timur (Desa Keboharan dan Desa Terung Wetan. Namun pada tahun 2005 dan 2015 Desa Keboharan dan Terun wetan tidak berada pada titik yang paling tinggi. 

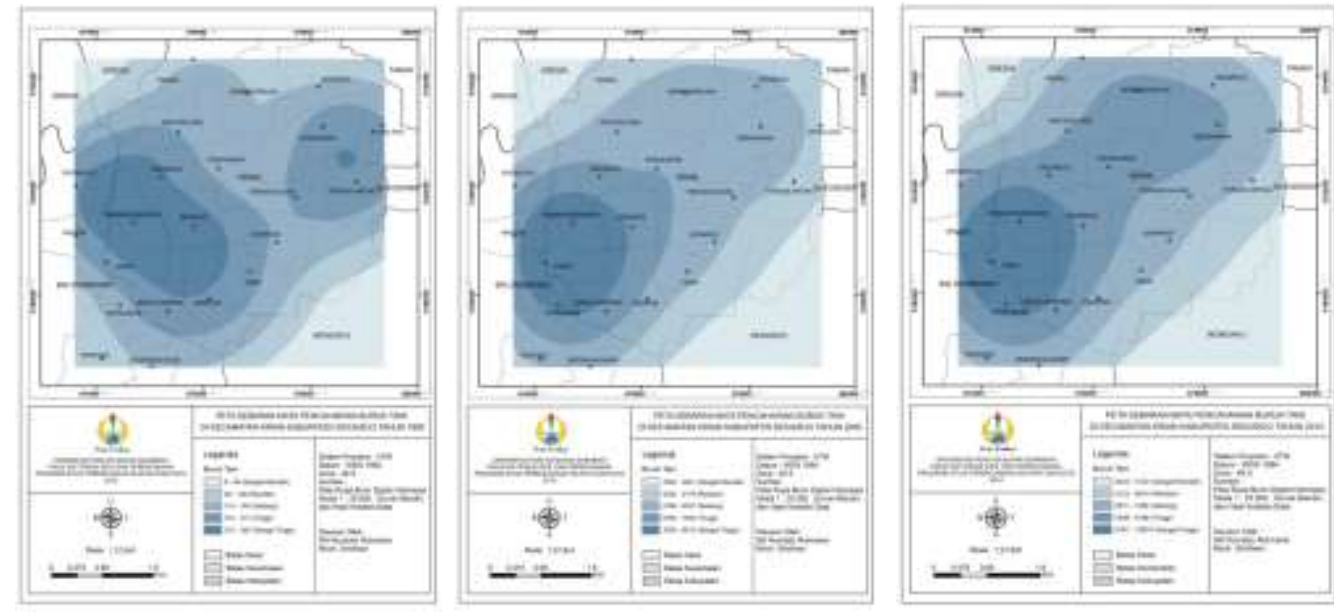

Gambar 2. Pola Perubahan Mata Pencaharian Petani Sejak Tahun 1995, 2005, 2015
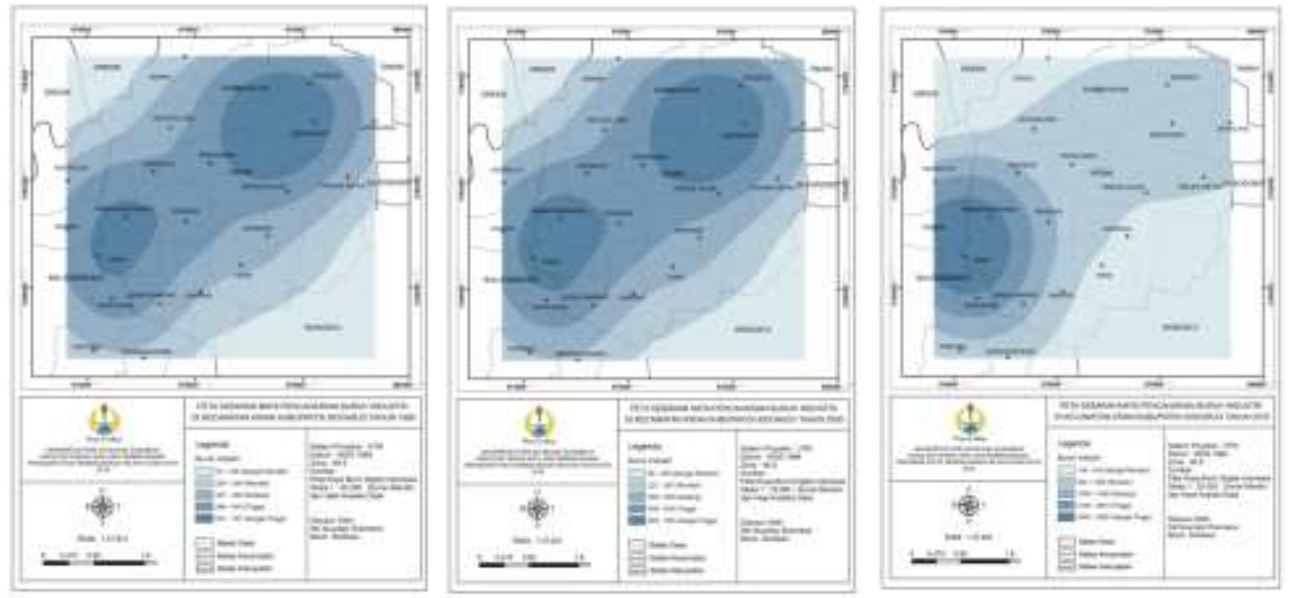

Gambar 3. Pola Perubahan Mata Pencaharian Buruh Sejak Tahun 1995, 2005, 2015

Lain halnya dengan pola perubahan mata pencaharian buruh industri, pola perubahan terjadi setelah tahun 2005. Sehingga dapat disimpulkan bahwa pola perubahan mata pencaharian terfokus di daerah barat Kabupaten Sidoarjo. Hal ini disebabkan di sisi timur secara administrasi lokasi tersebut strategis yaitu terletak di pertigaan bypass dan dibagian utara berbatasan dengan kabupaten Gresik. Sehingga memicu adanya perubahan aktivitas, yaitu sebagai tempat hunian. Artinya di sisi timur Sidoarjo tidak digunakan sebagai tempat aktivitas kerja masyarakat melainkan sebagai tempat tinggal.

\section{KESIMPULAN}

Kecamatan Krian merupakan salah satu daerah yang mengalami proses urbanisasi. Hal ini dibuktikan adanya perubahan lahan cukup tinggi. Dampak dari perubahan lahan yaitu adanya pola perubahan mata pencaharian. Berdasarkan hasil analisis bahwa perubahan mata pencaharian berada di sisi timur Kabupaten Sidoarjo. Hal ini disebabkan di sisi timur secara administrasi lokasi tersebut strategis yaitu terletak di pertigaan bypass dan dibagian utara berbatasan dengan kabupaten Gresik. Sehingga memicu adanya perubahan aktivitas, yaitu sebagai tempat hunian. Artinya di sisi timur Sidoarjo tidak digunakan sebagai tempat aktivitas kerja masyarakat melainkan sebagai tempat tinggal.

\section{UCAPAN TERIMA KASIH}

Penelitian ini telah mendapatkan dukungan dari Kementerian Pendidikan Tinggi T.A 2018, Fakultas Teknik Sipil dan Perencanaan, Program Studi Perencanaan Wilayah dan Kota Universitas PGRI Adi Buana Surabaya. 


\section{DAFTAR PUSTAKA}

Aguilar, A. G. (2008). Peri-urbanization, illegal settlements and environmental impact in Mexico City, 25, 133-145. http://doi.org/10.1016/j.cities.2008.02.003

Manaugh, K., Badami, M. G., \& El-geneidy, A. M. (2015). Integrating social equity into urban transportation planning: A critical evaluation of equity objectives and measures in transportation plans in North America. Transport Policy, 37, 167176. http://doi.org/10.1016/j.tranpol.2014.09.013

Samat, N. (2011). Modelling Land Use Changes at the Peri-Urban Areas Using Geographic Information Systems and Cellular Automata Model, 4(6), 72-84. http://doi.org/10.5539/jsd.v4n6p72

Simon, D. (2008). Urban Environments: Issues on the Peri-Urban Fringe. http://doi.org/10.1146/annurev.environ.33.021407.093240

Xiao, J., Shen, Y., Ge, J., Tateishi, R., \& Tang, C. (2006). Evaluating urban expansion and land use change in Shijiazhuang, China, by using GIS and remote sensing, 75, 69-80. http://doi.org/10.1016/j.landurbplan.2004.12.005

Yunus, H. 2008. Dinamika Wilayah Peri-Urban (Determinan Masa Depan Kota).Pustaka Pelajar : Yogyakarta 